\title{
Variabilidade espacial de atributos da fertilidade de um Latossolo Vermelho Distroférrico sob Sistema Plantio Direto ${ }^{1}$
}

\author{
Spatial variability of the fertility attributes of Dystropheric Red Latosol under a no- \\ tillage system
}

\author{
Flávio Carlos Dalchiavon ${ }^{2 *}$, Morel de Passos e Carvalho ${ }^{3}$, Marcelo Andreotti ${ }^{3}$ e Rafael Montanari ${ }^{4}$
}

\begin{abstract}
RESUMO - O conhecimento da variabilidade espacial da fertilidade do solo é muito importante, principalmente, para a agricultura de precisão. Assim, durante o ano agrícola 2009/2010, no município de Selvíria (MS), no Cerrado Brasileiro, objetivou-se analisar a variabilidade espacial de atributos da fertilidade num Latossolo Vermelho Distroférrico sob plantio direto. Foi instalada a malha de amostragem para a coleta de solo, com 120 pontos amostrais, numa área de 3,0 ha e declive homogêneo de $0,055 \mathrm{~m} \mathrm{~m}^{-1}$. Foram determinados os teores de $\mathrm{P}$ disponível, de matéria orgânica, valor de $\mathrm{pH}\left(\mathrm{CaCl}_{2}\right)$, teores de $\mathrm{K}^{+}, \mathrm{Ca}^{+2}, \mathrm{Mg}^{+2}$, valores de saturação por bases e por alumínio, nas profundidades de 0-0,10 m e 0,10-0,20 m. Efetuou-se a análise descritiva clássica, com auxílio do software estatístico SAS, e em seguida foram modelados semivariogramas para todos os atributos, obtendo-se as respectivas validações cruzadas e mapas de krigagens com o GS+ 7.0. As maiores variabilidades dos atributos químicos analisadas pelo coeficiente de variação ocorreram na camada de 0,10-0,20 m de profundidade do solo. Todos os atributos químicos pesquisados apresentaram dependência espacial, sendo possível mapear a área em estudo. Por representar a continuidade espacial dos semivariogramas obtidos no presente estudo, os valores dos alcances geoestatísticos recomendados para os atributos ora pesquisados deverão estar compreendidos entre 40,2 e 113,1 metros.
\end{abstract}

Palavras-chave: Agricultura de precisão. Fertilidade do solo. Geoestatística. Mapa de krigagem.

\begin{abstract}
Knowledge of the spatial variability of soil fertility is very important, especially in precision agriculture. Thus during the 2009/2010 agricultural year, in the city of Selva (MS) in the Brazilian Cerrado, the objective was to analyse the spatial variability of the fertility attributes of a Dystropheric Red Latosol under a no-tillage system. A sampling grid was installed to collect soil samples, with 120 sampling points in an area of 3.0 ha and on an even slope of $0.055 \mathrm{~m} \mathrm{~m}^{-1}$. The available phosphorus content, organic matter content, values of $\mathrm{pH}\left(\mathrm{CaCl}_{2}\right)$, levels of $\mathrm{K}^{+}, \mathrm{Ca}^{+2}, \mathrm{Mg}^{+2}$, values of base and aluminum saturation were all determined at depths of 0 to $0.10 \mathrm{~m}$ and 0.10 to $0.20 \mathrm{~m}$. A classic descriptive analysis was carried out with the help of the SAS statistical software, and semivariograms were then modeled for all attributes, giving the respective cross-validations and kriging chartswith the GS ${ }^{+} .0$ software. The largest variability, in the chemical attributes analysed by the coefficient of variation, occurred in the soil-depth layer of $0.10-0.20 \mathrm{~m}$. All studied chemical attributes showed spatial dependence, it being possible to map the study area. As they represent the spatial continuity of the semivariograms obtained in this study, the values of the geostatistical ranges recommended for those attributes here studied, should be between 40.2 and 113.1 metres.
\end{abstract}

Key words: Precision Agriculture. Soil fertility. Geostatistics. Kriging chart.

\footnotetext{
* Autor para correspondência

${ }^{1}$ Recebido para publicação em 11/12/2010; aprovado em 14/02/2012

Parte da Dissertação de Mestrado em Agronomia do primeiro autor

${ }^{2}$ Programa de Pós-Graduação em Agronomia, Faculdade de Engenharia de Ilha Solteira/UNESP, Rua Balsas 111, Zona Norte, Ilha Solteira-SP, Brasil, 15.385-000, fcdalchiavon@hotmail.com

${ }^{3}$ Departamento de Fitossanidade, Engenharia Rural e Solos, Universidade Estadual Paulista, Av. Brasil, 56, Centro, Ilha Solteira-SP, Brasil, 15.385-000, morel@agr.feis.unesp.br, dreotti@agr.feis.unesp.br

${ }^{4}$ Universidade Estadual de Mato Grosso do Sul/UEMS, Unidade Universitária de Aquidauana, Rodovia Aquidauana-UEMS, km 12, Aquidauana-MS, Brasil, 79.200-000, rafamontana@uems.br
} 


\section{INTRODUÇÃO}

No sistema plantio direto (SPD) a adoção de certas práticas de manejo (aplicação superficial uniforme do calcário, ausência de revolvimento do solo, adubações em superfície, a lanço ou nas linhas de semeadura, bem como o acúmulo superficial dos resíduos das culturas usadas em sucessão e/ou rotação ao longo dos anos) alteram a variabilidade dos atributos químicos do solo em relação ao sistema convencional, tanto vertical quanto horizontalmente, dessa forma, a variabilidade é fundamental para o estabelecimento do correto manejo da fertilidade do solo (ZANÃO JÚNIOR et al., 2010).

No entanto, à luz da estatística clássica, normalmente ao se analisar os atributos do solo, as conseqüências da heterogeneidade espacial sobre a representatividade dos valores médios são ignoradas (CHAVES; FARIAS, 2009). Em contrapartida, o método geoestatístico, além de analisar a dependência espacial desses valores, ainda proporciona meios para que sejam efetuados os respectivos mapeamentos da área estudada por meio da krigagem, uma vez que o modelo da dependência espacial seja conhecido por meio do semivariograma (LEMOS FILHO et al., 2008; SILVA et al., 2010). O semivariograma é um gráfico que caracteriza a estrutura da variância do atributo estudado como variável regionalizada em função da distância no terreno.

O conhecimento da variabilidade espacial dos atributos de solo e de cultura apresenta-se como ferramenta vantajosa para analisar a variabilidade de rendimento verificada e aperfeiçoar o manejo em áreas agrícolas por meio de um gerenciamento agrícola que leve em consideração informações pontuais de solo e de culturas (AMADO et al., 2009; MENDES; FONTES; OLIVEIRA, 2008; SILVA et al., 2003). Isso é possível através do estabelecendo de zonas específicas de manejo visando à conservação do solo (por exemplo a aplicação de insumo com taxa variada), condições necessárias à agricultura de precisão (AP).

$\mathrm{O}$ processo de adoção da AP encontra-se na fase em que o agricultor busca solucionar os principais problemas levantados em sua lavoura, através de mapas de produtividade e de fertilidade (WERNER et al., 2007). Para isso, a AP concilia o uso de tecnologias para o manejo diferenciado do solo, insumos e culturas, visando à produtividade das mesmas. Nesse contexto, a análise detalhada da variabilidade dos atributos do solo pode indicar alternativas de manejo para a redução dos efeitos da sua variabilidade sobre a produção das culturas. Assim, devido tanto ao recém surgimento como à inquestionável importância prática da $\mathrm{AP}$, ultimamente no Brasil os estudos geoestatísticos visando conhecer melhor a dinâmica dos atributos químicos no solo em SPD, vêm se intensificando. Como exemplos, destacamse os trabalhos de Zanão Júnior et al. (2007), Amado et al. (2009) e Zanão Júnior et al. (2010), cujos valores dos alcances da dependência espacial obtidos pelos referidos autores variaram entre 27,0 e $539,0 \mathrm{~m}$.

Tendo em vista que para o estabelecimento de práticas sustentáveis de manejo do solo e das culturas é necessário o conhecimento dos padrões de distribuição dos atributos químicos no solo, o presente trabalho teve como objetivo analisar a variabilidade espacial de atributos químicos do solo num Latossolo Vermelho Distroférrico sob sistema de plantio direto.

\section{MATERIAL E MÉTODOS}

$\mathrm{O}$ experimento foi desenvolvido na área experimental da Fazenda de Ensino e Pesquisa - Setor de Produção Vegetal, da Faculdade de Engenharia de Ilha Solteira (FEIS/UNESP), localizada no município de Selvíria (MS), localizada a 51'24'21" de longitude Oeste e 20'20'56" de latitude Sul, com a altitude média de $300 \mathrm{~m}$. O clima é classificado como Aw, segundo preceitos de Köppen, caracterizado como tropical úmido com estação chuvosa no verão e seca no inverno. Conforme preceitos do Sistema Brasileiro de Classificação de Solos (EMPRESA BRASILEIRADE PESQUISAAGROPECUÁRIA, 2006), o solo local é um Latossolo Vermelho Distroférrico típico muito argiloso, com declive homogêneo de $0,055 \mathrm{~m} \mathrm{~m}^{-1}$.

O solo estudado vem sendo cultivado há doze anos no sistema plantio direto, com a seguinte rotação das culturas (1 - soja, 2 - milho e 3 - algodão) sucedida das culturas invernais ( 1 - aveia preta, 2 - feijão e 3 - milho). A recomendação da correção do solo bem como de adubação das culturas são realizadas conforme Raij et al. (1996). No ano de 2008 foi aplicado calcário em superfície $(1,5$ ton ha ${ }^{-1}$ ) objetivando elevar a saturação por bases a $50 \%$. No ano de 2008/2009 foi cultivada soja no verão e milho no inverno, e em 2009/2010 foi cultivado arroz, sendo utilizado na sua adubação de base, recomendada conforme análise química do solo, $100 \mathrm{~kg} \mathrm{ha}^{-1}$ da formulação 08-2816 ( $\mathrm{N}-\mathrm{P}_{2} \mathrm{O}_{5}-\mathrm{K}_{2} \mathrm{O}$ ), e em cobertura $80 \mathrm{~kg} \mathrm{ha}^{-1} \mathrm{de} \mathrm{N}$ (sulfato de amônio), parcelado em 2 aplicações.

A coleta das amostras de solo foi realizada logo após a colheita do arroz, em março de 2010. Para isso foram definidas as direções $\mathrm{x}$ e $\mathrm{y}$ do sistema de coordenadas cartesianas, efetuando-se o estaqueamento global e aleatório da malha experimental, com 120 pontos amostrais em uma área de 3,0 ha $(322 \times 93,35 \mathrm{~m})$, onde cada ponto amostral ficou constituído de uma área media de $250 \mathrm{~m}^{2}$. 
Os atributos químicos do solo avaliados foram os teores de fósforo disponível $(\mathrm{P})$, matéria orgânica (MO), valor de $\mathrm{pH}$ em $\mathrm{CaCl}_{2}$, teores de potássio $\left(\mathrm{K}^{+}\right)$, cálcio $\left(\mathrm{Ca}^{+2}\right)$, magnésio $\left(\mathrm{Mg}^{+2}\right)$, valores de saturação por bases (V\%) e saturação por alumínio (m\%), sendo as amostras de solo coletadas entre as linhas de semeadura do arroz e estratificadas em duas profundidades: a) 0-0,10 m, representada pelo índice 1 , e b) 0,10-0,20 m, representada pelo índice 2. O solo foi seco ao ar (TFSA), destorroado mecanicamente, passado por uma peneira com malha de $2 \mathrm{~mm}$ e por fim analisado quimicamente, conforme Raij et al. (2001).

Para cada atributo estudado, efetuou-se a análise descritiva clássica, com auxílio do software estatístico SAS, em que foram calculados a média, mediana, valores mínimos e máximos, desvio-padrão, coeficiente de variação, curtose, assimetria e a distribuição de frequência. Posteriormente, realizou-se a identificação dos outliers, que são valores que estão três vezes além do intervalo interquantílico do Box Plot no gráfico de ramos e folhas, efetuando a substituição dos seus valores pelo valor médio dos circunvizinhos contidos na malha geoestatística. Para testar a hipótese da normalidade, ou da lognormalidade, realizou-se o teste de Shapiro e Wilk (1965) a 5\%, utilizado quando o tamanho da amostra é menor que 2.000 observações (SCHLOTZHAVER; LITTELL, 1999).

Para cada atributo foi analisada a dependência espacial pelo cálculo do semivariograma simples, com base nos pressupostos de estacionaridade da hipótese intrínseca pelo uso do pacote Gamma Design Software 7.0 - $G S^{+}$(GDS, 2004). Os ajustes dos semivariogramas, em função de seus modelos, foram efetuados prioritariamente pela seleção inicial de: 1) menor soma dos quadrados dos desvios (RSS); 2) maior coeficiente de determinação $\left(\mathrm{R}^{2}\right)$, e 3) maior avaliador da dependência espacial (ADE). Entretanto, para os atributos (ATR) que não apresentaram dependência espacial, istoé, na ausência de estacionaridade, retirou-se a tendência dos dados por meio da técnica da regressão múltipla polinomial, conforme preceitos de Davis (1986). Assim, eles ficaram precedidos do símbolo \# quando referidos na tabela da análise semivariográfica e da validação cruzada (\#ATR). Já quando referidos no mapa de krigagem, ficaram precedidos por $£$ (£ATR).

A decisão final do modelo que representou o ajuste foi atestada pela validação cruzada, assim como para a definição do tamanho da vizinhança que proporcionou a melhor malha de krigagem. Para cada atributo foram relacionados o efeito pepita $\left(\mathrm{C}_{\mathrm{o}}\right)$, o patamar $\left(\mathrm{C}_{\mathrm{o}}+\mathrm{C}\right)$ e o alcance $\left(A_{o}\right)$. A análise do avaliador da dependência espacial (ADE) foi efetuada conforme a Equação 1 (GDS, 2004):

$\mathrm{ADE}=\left[\mathrm{C} /\left(\mathrm{C}+\mathrm{C}_{\mathrm{o}}\right)\right] \times 100$ onde: ADE é o avaliador da dependência espacial; $\mathrm{C}$, a variância estrutural; e $\mathrm{C}+\mathrm{C}_{\mathrm{o}}$, o patamar. A interpretação proposta para o $\mathrm{ADE}$ foi a seguinte: a) $\mathrm{ADE}<20 \%=$ variável espacial de muito baixa dependência (MB); b) $20 \% \leq \mathrm{ADE}<40 \%=$ baixa dependência (BA); c) $40 \% \leq \mathrm{ADE}<60 \%=$ média dependência (ME); d) $60 \% \leq \mathrm{ADE}<80 \%=$ alta dependência $(\mathrm{AL})$ e e) $80 \% \leq \mathrm{ADE}<100 \%=$ muito alta dependência (MA).

\section{RESULTADOS E DISCUSSÃO}

Avariabilidade de um atributo pode ser classificada segundo a magnitude de seu coeficiente de variação (CV), classificando-o como baixo $(\mathrm{CV} \leq 10 \%)$, médio $(10 \%<$ $\mathrm{CV} \leq 20 \%)$, alto $(20 \%<\mathrm{CV} \leq 30 \%)$ e muito alto $(\mathrm{CV}>$ $30 \%$ ). Desta forma, observa-se que para a profundidade de 0-0,20 m de solo analisada, os CV's foram classificados como baixo, médio e muito alto, ao passo que para a profundidade de 0,10-0,20 $\mathrm{m}$ foi, além destes, também alto (Tabela 1). Segundo Carvalho, Takeda e Freddi (2003), a variabilidade dos atributos químicos do solo é conseqüência de complexas interações dos processos de sua formação e de práticas de manejo do solo e da cultura, com impacto principalmente nas camadas superficiais do solo. Entretanto, no presente estudo, a variabilidade nos dados dos atributos possivelmente esteve associada ao efeito de cultivos sucessivos em SPD, com a adubação em linha e em diferentes espaçamentos.

De acordo com as classes de fertilidade do solo ( $\mathrm{P}, \mathrm{pH}, \mathrm{K}, \mathrm{Ca}, \mathrm{Mg}$ e $\mathrm{V} \%$ ) propostas por Raij et al. (1996), do teor de matéria orgânica (ALVES et al., 2009) e do índice de saturação por alumínio (FONTES; FONTES, 1992), foi possível conhecer a dinâmica dos referidos atributos no presente trabalho. Assim, o $\mathrm{P}$ $\left(\mathrm{P} 1=20,7 \mathrm{mg} \mathrm{dm}^{-3} ; \mathrm{P} 2=23,6 \mathrm{mg} \mathrm{dm}^{-3}\right)$ apresentou teor médio no solo (Tabela 1). O aumento do seu teor em profundidade pode estar relacionado ao SPD pelo não revolvimento do solo, o que reduz o contato entre os colóides e o íon fosfato, amenizando as reações de adsorção, sobretudo pela adubação ter sido realizada na linha de semeadura, e ao P-orgânico oriundo da decomposição dos restos de raízes remanescentes ao longo do perfil do solo, constituindo importante reserva de P-lábil para as plantas nas camadas mais profundas do solo.

Apesar de os níveis de matéria orgânica no solo se apresentarem diferentemente entre as camadas avaliadas (Tabela 1), ambas estavam na faixa de médio teor (15$30 \mathrm{~g} \mathrm{dm}^{-3}$ ). Uma das características marcantes do SPD é o aumento do teor de MO na camada superficial do solo (0-0,10 m) com o decorrer do tempo de implantação do sistema, reflexo da ausência de preparo do solo, da 
Tabela 1 - Análise descritiva dos atributos químicos de um Latossolo Vermelho Distroférrico sob sistema plantio direto, nas profundidades de $0-0,10 \mathrm{~m}$ e $0,10-0,20 \mathrm{~m}$

\begin{tabular}{|c|c|c|c|c|c|c|c|c|c|c|}
\hline \multirow{3}{*}{ Atributo $^{(a)}$} & \multicolumn{10}{|c|}{ Medidas estatísticas descritivas } \\
\hline & \multirow{2}{*}{ Média } & \multirow{2}{*}{ Mediana } & \multicolumn{2}{|c|}{ Valor } & \multirow{2}{*}{$\begin{array}{l}\text { Desvio } \\
\text { Padrão }\end{array}$} & \multicolumn{3}{|c|}{ Coeficiente } & \multicolumn{2}{|c|}{$\begin{array}{c}\text { Probabilidade } \\
\text { do teste }^{(\mathrm{b})}\end{array}$} \\
\hline & & & Mínimo & Máximo & & $\begin{array}{c}\text { Variação } \\
(\%)\end{array}$ & Curtose & Assimetria & $\operatorname{Pr}<w$ & $\mathrm{DF}$ \\
\hline $\mathrm{P} 1\left(\mathrm{mg} \mathrm{dm}^{-3}\right)$ & 20,7 & 16,5 & 6,0 & 66,0 & 11,96 & 57,82 & 0,532 & 0,268 & 0,060 & $\mathrm{LN}$ \\
\hline $\mathrm{P} 2\left(\mathrm{mg} \mathrm{dm}^{-3}\right)$ & 23,6 & 14,0 & 4,0 & 92,0 & 20,65 & 87,61 & 2,071 & 1,632 & $10-4$ & ND \\
\hline $\operatorname{MO1}\left(\mathrm{g} \mathrm{dm}^{-3}\right)$ & 25,6 & 25,0 & 19,0 & 34,0 & 3,30 & 12,93 & $-0,323$ & 0,342 & 0,001 & ND \\
\hline $\mathrm{MO} 2\left(\mathrm{~g} \mathrm{dm}^{-3}\right)$ & 20,1 & 20,0 & 12,0 & 28,0 & 2,96 & 14,76 & 0,223 & 0,126 & 0,005 & ND \\
\hline pH1 & 4,9 & 4,8 & 4,2 & 6,0 & 0,38 & 7,80 & 0,096 & 0,666 & 0,001 & ND \\
\hline $\mathrm{pH} 2$ & 4,6 & 4,6 & 4,0 & 5,6 & 0,32 & 6,91 & 0,605 & 0,726 & $5.10-4$ & ND \\
\hline $\mathrm{K} 1\left(\mathrm{mmol}_{\mathrm{c}} \mathrm{dm}^{-3}\right)$ & 3,0 & 2,7 & 0,6 & 7,5 & 1,56 & 51,81 & $-0,449$ & $-0,342$ & 0,043 & $\mathrm{LN}$ \\
\hline $\mathrm{K} 2\left(\mathrm{mmol}_{\mathrm{c}} \mathrm{dm}^{-3}\right)$ & 2,2 & 2,0 & 0,4 & 5,7 & 1,29 & 59,43 & 0,277 & 0,834 & $10-4$ & ND \\
\hline $\mathrm{Ca} 1\left(\mathrm{mmol}_{\mathrm{c}} \mathrm{dm}^{-3}\right)$ & 21,5 & 20,0 & 10,0 & 41,0 & 7,76 & 36,13 & $-0,850$ & 0,027 & 0,037 & $\mathrm{TL}$ \\
\hline $\mathrm{Ca} 2\left(\mathrm{mmol}_{\mathrm{c}} \mathrm{dm}^{-3}\right)$ & 14,3 & 13,0 & 4,0 & 32,0 & 5,43 & 38,05 & 0,314 & $-0,168$ & 0,182 & $\mathrm{LN}$ \\
\hline $\operatorname{Mg} 1\left(\mathrm{mmol}_{\mathrm{c}} \mathrm{dm}^{-3}\right)$ & 15,3 & 14,0 & 6,0 & 31,0 & 5,61 & 36,69 & $-0,879$ & $-0,020$ & 0,024 & $\mathrm{TL}$ \\
\hline $\operatorname{Mg} 2\left(\mathrm{mmol}_{\mathrm{c}} \mathrm{dm}^{-3}\right)$ & 9,9 & 9,5 & 3,0 & 24,0 & 4,07 & 41,19 & $-0,236$ & $-0,278$ & 0,141 & $\mathrm{LN}$ \\
\hline $\mathrm{V} \% 1$ & 43,7 & 43,4 & 19,4 & 74,4 & 12,74 & 29,13 & $-0,645$ & 0,324 & 0,026 & $\mathrm{TN}$ \\
\hline $\mathrm{V} \% 2$ & 31,1 & 29,9 & 9,4 & 66,7 & 11,10 & 35,74 & 0,334 & 0,583 & 0,022 & $\mathrm{TN}$ \\
\hline $\mathrm{m} \% 1$ & 14,6 & 10,1 & 0,0 & 49,9 & 13,28 & 91,27 & $-0,398$ & 0,810 & $10-4$ & ND \\
\hline $\mathrm{m} \% 2$ & 31,4 & 30,7 & 0,0 & 76,9 & 19,17 & 61,11 & $-0,645$ & 0,230 & 0,026 & ND \\
\hline
\end{tabular}

${ }^{(a)} \mathrm{P}, \mathrm{MO}, \mathrm{pH}, \mathrm{K}, \mathrm{Ca}, \mathrm{Mg}, \mathrm{V} \%$ e m\% são respectivamente o fósforo, matéria orgânica, potencial hidrogeniônico, potássio, cálcio, magnésio, saturação por bases e saturação por alumínio; ${ }^{(b)}$ teste de Shapiro e Wilk; DF = distribuição de frequência, sendo LN, ND, TL e TN respectivamente do tipo lognormal, não determinada, tendendo a lognormal e tendendo a normal

quantidade e da qualidade dos resíduos das culturas ao longo dos anos. A razão do acréscimo de MO decorre do fato de a taxa de decomposição da palha mantida na superfície do solo ser menor do que se fosse incorporada. Em consequência, a alteração no teor de MO, tanto em quantidade como em qualidade, tem implicações graduais nas alterações do $\mathrm{pH}$ (associada aos seus teores de cátions de reação básica e carbono orgânico solúvel) e na toxidez por Al, por meio de hidrólise ou complexação por ácidos orgânicos, conforme salientado por Zanão Júnior et al. (2007).

Os valores de $\mathrm{pH}(\mathrm{pH} 1=4,9 ; \mathrm{pH} 2=4,6)$, como pode ser verificado na Tabela 1 , classificaram o solo como de acidez alta (pH entre 4,4 e 5,0). Tal fato ocorreu em função de que a correção da acidez do solo em 2008 foi efetuada para atingir uma saturação por bases de $50 \%$. Por outro lado, a diminuição do $\mathrm{pH}$ em profundidade foi decorrente dos menores teores de bases trocáveis nessas regiões do solo. Em relação aos menores teores das bases trocáveis $\left(\mathrm{K} 1=3,0 \mathrm{mmol}_{\mathrm{c}} \mathrm{dm}^{-3}\right.$ e K2 $=2,2 \mathrm{mmol}_{\mathrm{c}}$ $\mathrm{dm}^{-3} ; \mathrm{Ca} 1=21,5 \mathrm{mmol}_{\mathrm{c}} \mathrm{dm}^{-3}$ e Ca2 $=14,3 \mathrm{mmol}_{\mathrm{c}} \mathrm{dm}^{-3}$;
$\mathrm{Mg} 1=15,3 \mathrm{mmol} \mathrm{dm}^{-3}$ e $\mathrm{Mg} 2=9,9 \mathrm{mmol} \mathrm{dm}^{-3}$ ) e da $\mathrm{V} \%(\mathrm{~V} \% 1=43,7$ e V\%2 de 31,1) em profundidade, este fato já havia sido constatado por Costa et al. (2007) num Latossolo Vermelho Distroférrico sob plantio direto. Segundo estes autores, a tendência é de que ocorra redução dos teores das bases trocáveis à medida que aumenta a profundidade do solo, uma vez que o efeito da calagem nessas regiões é menos intenso.

Em virtude da reciclagem do $\mathrm{K}$ como resultado do acúmulo dos resíduos das culturas em rotação no SPD, ocorreu uma maior disponibilidade nos primeiros $0,10 \mathrm{~m}$ de solo. Isso permite, então, que possam ser adicionadas doses menores de adubação de manutenção, sem que a produtividade das culturas seja afetada. Foi constatado ainda que no complexo coloidal do solo (Tabela 1), o K apresentou teor de média disponibilidade $\left(1,6-3,0 \mathrm{mmol}_{\mathrm{c}} \mathrm{dm}^{-3}\right)$, enquanto que o $\mathrm{Ca}\left(>7 \mathrm{mmol}_{\mathrm{c}} \mathrm{dm}^{-3}\right)$ e o $\mathrm{Mg}\left(>8 \mathrm{mmol}_{\mathrm{c}} \mathrm{dm}^{-3}\right)$ estavam presentes em alta disponibilidade. Contudo, foi verificada uma baixa V\% (26-50\%), indicando que a acidez potencial contribuiu com a maior parte da saturação do complexo coloidal do solo. 
Em relação ao índice $\mathrm{m} \%$, os resultados indicaram que o solo é distrófico $(\mathrm{m} \%<50)$, uma vez que seus índices satisfizeram tal condição (Tabela 1). Entretanto, uma ligeira elevação da $\mathrm{m} \%$ foi observada na profundidade de $0,10-0,20 \mathrm{~m}$. O acréscimo da $\mathrm{m} \%$ em profundidade pode ser atribuído aos menores efeitos das bases trocáveis nessas regiões, que podem estar mais relacionadas a fontes orgânicas predominantes na superfície do solo, conforme destacaram Costa et al. (2007). Em contrapartida, a redução da m\% na superfície do solo em SPD está relacionada à complexação orgânica do alumínio trocável por compostos solúveis presentes nos restos vegetais mantidos na superfície do solo (ZANÃO JÚNIOR et al., 2007).

Apesar de os dados não apresentarem distribuições simétricas, os coeficientes de assimetria e curtose próximos de zero, assim como valores médios e medianos próximos para a maioria dos atributos, permitem que lhes sejam aplicados tratamentos geoestatísticos (CHAVES; FARIAS, 2009), possibilitando avaliar a dependência espacial dos atributos, pois, na geoestatística, mais importante que a normalidade dos dados é a ocorrência ou não do efeito proporcional em que a média e a variância dos dados não sejam constantes na área de estudo.
Assim, na Tabela 2 estão apresentados os parâmetros dos semivariogramas ajustados, podendo-se constatar que todos os atributos pesquisados apresentaram dependência espacial. A dependência espacial denotou que o comportamento dessas variáveis regionalizadas não foi aleatório e que as distâncias entre pontos utilizadas na malha geoestatística foram suficientes para o estudo da variabilidade espacial, em ambas as profundidades.

O desempenho dos semivariogramas, analisado pela relação decrescente dos seus respectivos coeficientes de determinação espacial $\left(\mathrm{r}^{2}\right)$, foi o seguinte: 1) V\%1 $(0,996)$, 2) $\mathrm{MO} 2(0,993), 3) \mathrm{Ca} 1(0,989), 4) \mathrm{pH} 1(0,969), 5) \mathrm{Mg} 2$ $(0,968), 6) \mathrm{Ca} 2(0,963), 7)$ \#K2 $(0,957), 8) \mathrm{V} \% 2(0,946)$, 9) $\mathrm{pH} 2(0,942), 10) \mathrm{m} \% 1(0,941), 11) \mathrm{MO} 1(0,883), 12)$ $\mathrm{m} \% 2$ (0,878), 13) Mg1 (0,850), 14) P1 (0,834), 15) P2 $(0,782)$ e 16) \#K1 (0,732), conforme a Tabela 2.

Por outro lado, na Tabela 2 podem ser visualizados ainda os valores dos alcances geoestatísticos dos atributos, que ficaram entre 113,1 m (Mg1) e 40,2 m (\#K2), conforme o atributo analisado. Por outro lado, nenhum dos atributos apresentou o mesmo valor do alcance para ambas as profundidades de solo analisadas, denotando, além da variabilidade vertical, variabilidade horizontal

Tabela 2 - Parâmetros dos semivariogramas dos atributos químicos de um Latossolo Vermelho Distroférrico sob sistema plantio direto, nas profundidades de $0-0,10 \mathrm{~m}$ e $0,10-0,20 \mathrm{~m}$

\begin{tabular}{|c|c|c|c|c|c|c|c|c|c|c|c|}
\hline \multirow{3}{*}{ Atributo $^{(a)}$} & \multicolumn{11}{|c|}{ Parâmetros do ajuste } \\
\hline & \multirow{2}{*}{ Modelo $^{(\mathrm{b})}$} & \multirow{2}{*}{$\mathrm{C}_{\mathrm{o}}$} & \multirow{2}{*}{$\mathrm{C}_{\mathrm{o}}+\mathrm{C}$} & \multirow{2}{*}{$\mathrm{A}_{\mathrm{o}}(\mathrm{m})$} & \multirow{2}{*}{$r^{2}$} & \multirow{2}{*}{$\mathrm{SQR}^{(\mathrm{c})}$} & \multicolumn{2}{|c|}{$\mathrm{ADE}^{(\mathrm{d})}$} & \multicolumn{3}{|c|}{ Validação cruzada } \\
\hline & & & & & & & $\%$ & Classe & $\mathrm{a}$ & $\mathrm{b}$ & $\mathrm{r}$ \\
\hline $\mathrm{P} 1$ & $\exp (127)$ & $5,64.101$ & $1,26.102$ & 46,8 & 0,834 & $1,85.102$ & 55,2 & $\mathrm{ME}$ & $-2,00.10-1$ & 0,999 & 0,349 \\
\hline $\mathrm{P} 2$ & esf (89) & $1,49.102$ & $2,98.102$ & 93,4 & 0,782 & $4,90.103$ & 50,0 & ME & $8,90.10-1$ & 0,962 & 0,474 \\
\hline MO1 & esf (138) & 4,22 & $1,06.10$ & 50,1 & 0,883 & 2,17 & 60,3 & $\mathrm{AL}$ & 3,68 & 0,857 & 0,425 \\
\hline MO2 & esf (194) & 3,75 & 8,87 & 73,2 & 0,993 & $1,09.10-1$ & 57,7 & ME & $7,00.10-2$ & 0,998 & 0,518 \\
\hline pH1 & esf (278) & $3,06.10-2$ & $1,34.10-1$ & 62,0 & 0,969 & $1,28.10-4$ & 77,2 & $\mathrm{AL}$ & $4,50.10-1$ & 0,906 & 0,597 \\
\hline $\mathrm{pH} 2$ & esf (287) & $6,90.10-3$ & $8,50 \cdot 10-2$ & 60,0 & 0,942 & $1,32.10-4$ & 91,9 & MA & $8,60.10-1$ & 0,813 & 0,609 \\
\hline \#K1 & $\exp (65)$ & $1,52.10-1$ & 1,28 & 41,4 & 0,732 & $9,08.10-2$ & 88,1 & MA & $-3,00.10-2$ & 0,545 & 0,212 \\
\hline \#K2 & $\exp (113)$ & $1,13.10-1$ & $9,79.10-1$ & 40,2 & 0,957 & $4,75.10-3$ & 88,5 & MA & $-4,00.10-2$ & 0,461 & 0,187 \\
\hline $\mathrm{Ca} 1$ & $\exp (287)$ & $1,17.10$ & $6,30.10$ & 75,3 & 0,989 & 7,97 & 81,4 & MA & 2,87 & 0,860 & 0,542 \\
\hline $\mathrm{Ca} 2$ & esf (293) & 2,55 & $2,98.10$ & 57,7 & 0,963 & 9,71 & 91,4 & MA & 1,08 & 0,922 & 0,719 \\
\hline $\mathrm{Mg} 1$ & $\exp (458)$ & 8,30 & $3,51.10$ & 113,1 & 0,850 & 43,3 & 76,4 & $\mathrm{AL}$ & $7,70.10-1$ & 0,946 & 0,639 \\
\hline $\mathrm{Mg} 2$ & esf (330) & 1,40 & $1,69.10$ & 71,4 & 0,968 & 3,44 & 91,7 & MA & $6,90.10-1$ & 0,926 & 0,731 \\
\hline $\mathrm{V} \% 1$ & esf (317) & $6,03.10$ & $1,68.102$ & 62,0 & 0,996 & $1,54.10$ & 64,1 & $\mathrm{AL}$ & 3,78 & 0,909 & 0,539 \\
\hline $\mathrm{V} \% 2$ & esf (316) & $1,06.10$ & $1,34.102$ & 56,8 & 0,946 & $2,83.102$ & 92,1 & MA & 2,47 & 0,915 & 0,722 \\
\hline $\mathrm{m} \% 1$ & esf (144) & $5,20.10$ & $1,83.102$ & 43,0 & 0,941 & $3,26.102$ & 71,5 & $\mathrm{AL}$ & 3,54 & 0,762 & 0,447 \\
\hline $\mathrm{m} \% 2$ & esf (256) & $3,25.10$ & $3,37.102$ & 54,6 & 0,878 & $3,90.103$ & 90,3 & MA & 4,13 & 0,877 & 0,671 \\
\hline
\end{tabular}

(a) $\mathrm{P}$ = fósforo, $\mathrm{MO}=$ matéria orgânica, $\mathrm{pH}=$ potencial hidrogeniônico, $\# \mathrm{~K}=$ potássio, $\mathrm{Ca}=$ cálcio, $\mathrm{Mg}=$ magnésio, $\mathrm{V} \%=$ saturação por bases e $\mathrm{m} \%$ = saturação por alumínio; parênteses sucedendo o modelo = número de pares no primeiro lag; ${ }^{(b)}$ exp $=$ exponencial e esf $=$ esférico; ${ }^{(c)} \mathrm{SQR}=$ soma dos quadrados dos resíduos; (d) $\mathrm{ADE}=$ avaliador da dependência espacial, sendo $\mathrm{ME}=$ média, $\mathrm{AL}=$ alta e MA = muito alta 
entre as profundidades, conforme já havia sido destacado por Corá et al. (2004).

Cabe salientar que o alcance é o principal parâmetro fornecido pela geoestatística, representando a distância na qual uma variável regionalizada apresenta continuidade espacial, sendo que a partir desta distância, o comportamento espacial da variável passa a ser totalmente aleatório (LEMOS FILHO et al., 2008). Seu conhecimento é de extrema importância à agricultura de precisão, uma vez que os programas computacionais o utilizam para poder monitorar o maquinário agrícola quando da aplicação de insumos com taxas variáveis (DALCHIAVON et al., 2011).

$\mathrm{O}$ valor do alcance geoestatístico pode influenciar a qualidade das estimativas, uma vez que ele determina o número de valores usados na interpolação, delimitando a extensão da correlaçãoespacial entre as amostras (MENDES; FONTES; OLIVEIRA, 2008). Assim, estimativas feitas com interpolação por krigagem utilizando valores de alcances maiores tendem a ser mais confiáveis, apresentando mapas que representam melhor a realidade (CORÁ et al., 2004). Portanto, a partir do ajuste dos semivariogramas, puderam perfeitamente ser construídos mapas de krigagem, que são fundamentais para a agricultura de precisão haja vista que a partir desses são definidas zonas especificas de manejo da fertilidade do solo, possibilitando a aplicação de insumos com taxas variadas, visando à homogeneização da fertilidade do solo.

Na profundidade de 0 a $0,10 \mathrm{~m}$, os modelos dos semivariogramas ajustados foram o exponencial (P1, \#K1, Ca1 e Mg1) e o esférico (MO1, pH1, V\%1 e m\%1). Entretanto, na profundidade de 0,10 a $0,20 \mathrm{~m}$, ajustouse predominantemente semivariogramas esféricos, excetuando-se o \#K2, que apresentou modelo exponencial (Tabela 2). Em relação ao avaliador da dependência espacial (ADE), foi observado que os maiores valores corresponderam aos atributos avaliados na profundidade de 0,10 a 0,20 m. Assim, com exceção do P2 e da MO2, que apresentaram média dependência espacial, os demais atributos apresentaram dependência espacial muito alta, variando entre 88,5\% (\#K2) e 92,1\% (V\%2).

Em contrapartida, na profundidade de 0 a $0,10 \mathrm{~m}$, as classes de dependência espacial dos atributos apresentaramse como média (P1), alta (MO1, pH1, Mg1, V\%1 e m\%1) e muito alta (\#K1 e Ca1), com valores do ADE variando entre 55,2 e $88,1 \%$ (Tabela 2). O efeito da calagem e da reciclagem superficial de nutrientes por meio da decomposição da matéria orgânica acumulada nessa camada de solo, possivelmente está relacionado com os valores diferenciados da dependência espacial entre as profundidades do solo, uma vez que a intensidade das reações também é distinta (DALCHIAVON, 2010).
Os mapas de krigagem foram elaborados de acordo com as classes de fertilidade do solo, e estratificados para as profundidades de 0 a $0,10 \mathrm{~m}$ (Figura 1 e 2) e 0,10 a 0,20 m (Figura 3 e 4). Segundo Zanão Júnior et al. (2010), este critério é mais coerente do que fazê-los conforme as classes sugeridas pelos programas que os geram. Isso porque as recomendações de adubação atuais são realizadas de acordo com as classificações dos níveis dos nutrientes no solo.

Neste sentido, o P apresentou teor médio (16,0$40,0 \mathrm{mg} \mathrm{dm}^{-3}$ ) na maior parte da área pesquisada (Figura 1 e 3). Na profundidade de 0 a $0,10 \mathrm{~m}$ apareceram algumas manchas com teores baixos $\left(7,0-15,0 \mathrm{mg} \mathrm{dm}^{-3}\right)$, ao passo que na profundidade de 0,10 a $0,20 \mathrm{~m}$, tais manchas apareceram em maior evidência e em todos os quadrantes. Ao norte do mapa, foi constatada ainda uma região isolada com predominância de teores altos $\left(41,0-80,0 \mathrm{mg} \mathrm{dm}^{-3}\right)$. Este comportamento do P está relacionado ao fato de que o nutriente é praticamente imóvel no solo, sendo envolvido em processos de fixação, que podem ser permanentes para a maioria dos solos tropicais. Este nutriente assume grande importância na produção agrícola, uma vez que é um dos nutrientes mais limitantes à produtividade das culturas (SILVA et al., 2010).

Apenas uma pequena mancha não apresentou teor médio (15,0-30,0 $\mathrm{g} \mathrm{dm}^{-3}$ ) de MO (Figura 1), representando uma região de maior fertilidade do solo. Para esta região, na direção sul, o teor de MO foi alto (30,0-50,0 $\left.\mathrm{g} \mathrm{dm}^{-3}\right)$. Já na profundidade de 0,10-0,20 m, a MO apresentou homogeneidade horizontal, com teor médio, conforme pode ser visualizado na Figura 3, ocasionado pela ausência de revolvimento do solo, característico do SPD (ZANÃO JÚNIOR et al., 2010).

O grau de acidez do solo indicado pelo seu valor de $\mathrm{pH}$, para a maior parte da área, e independentemente da profundidade de solo considerada, foi classificado como alto (4,4-5,0). Entretanto, ambientes de acidez média (5,1$5,5)$ e baixa $(5,6-6,0)$ também foram constatados (Figura 1 e 3). Especificamente para a profundidade de 0,10 a $0,20 \mathrm{~m}$, sítios que podem representar sérias restrições à produção agrícola foram mapeados, cujo índice de acidez foi muito alto $(\mathrm{pH}<4,3)$. Essa condição em subsuperfície está vinculada ao menor efeito do corretivo de acidez nessa região, uma vez que no SPD não há incorporação ao solo.

$\mathrm{O} \mathrm{K}$ apresentou aspecto de distribuição espacial heterogeneamente muito semelhante, quando analisadas as duas profundidades (Figura 1 e 3), com teores baixo $\left(0,8-1,5 \mathrm{mmol}_{\mathrm{c}} \mathrm{dm}^{-3}\right)$, médio $(1,6-3,0$ $\left.\mathrm{mmol}_{\mathrm{c}} \mathrm{dm}^{-3}\right)$ e alto $\left(3,1-6,0 \mathrm{mmol}_{\mathrm{c}} \mathrm{dm}^{-3}\right)$. Um pequeno halo com teor muito baixo $\left(0-0,7 \mathrm{mmol}_{\mathrm{c}} \mathrm{dm}^{-3}\right)$ foi mapeado na região noroeste (Figura 3). O Ca apresentou homogeneidade espacial, tanto vertical quanto horizontal 
Figura 1 - Mapas de krigagem dos atributos químicos (P, MO, $\mathrm{pH}$ e $£ \mathrm{~K}$ ) de um Latossolo Vermelho Distroférrico sob sistema plantio direto na profundidade de 0 a $0,10 \mathrm{~m}$
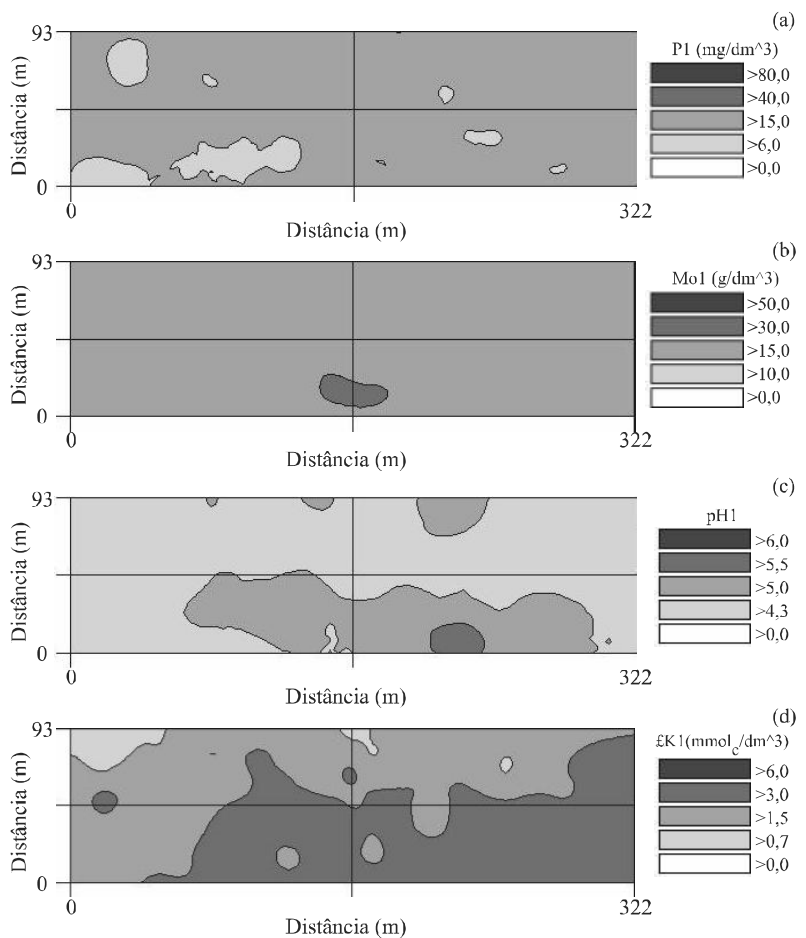

Figura 3 - Mapas de krigagem dos atributos químicos (P, MO, pH e £K) de um Latossolo Vermelho Distroférrico sob sistema plantio direto na profundidade de 0,10 a $0,20 \mathrm{~m}$
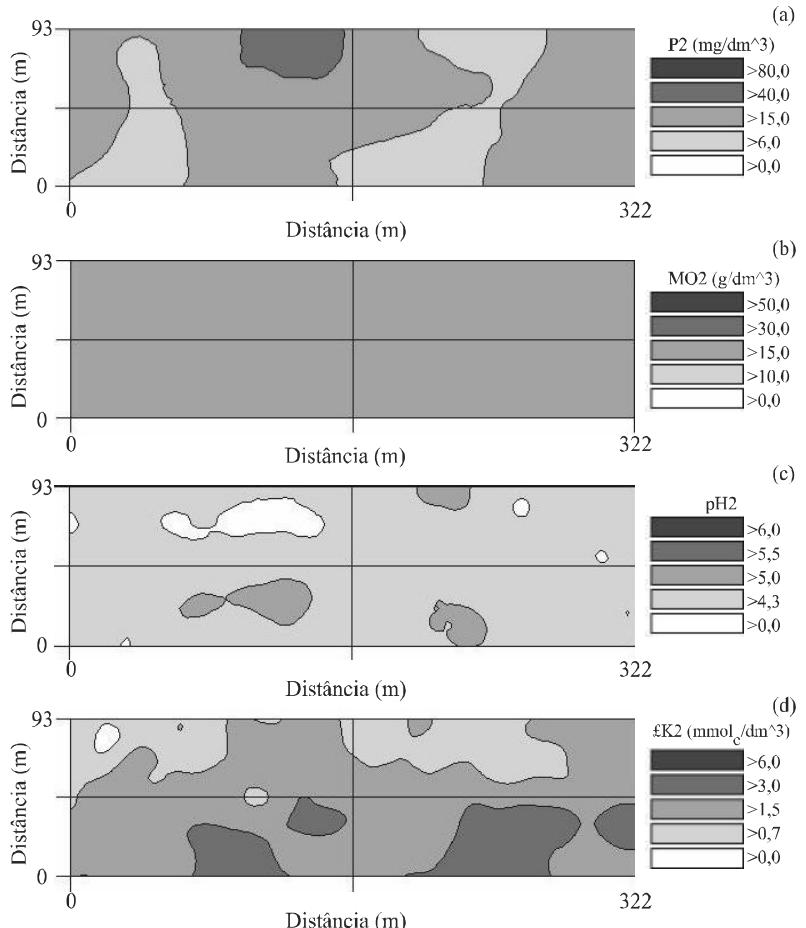

Figura 2 - Mapas de krigagem dos atributos químicos (Ca, $\mathrm{Mg}$, V\% e m\%) de um Latossolo Vermelho Distroférrico sob sistema plantio direto na profundidade de 0 a $0,10 \mathrm{~m}$
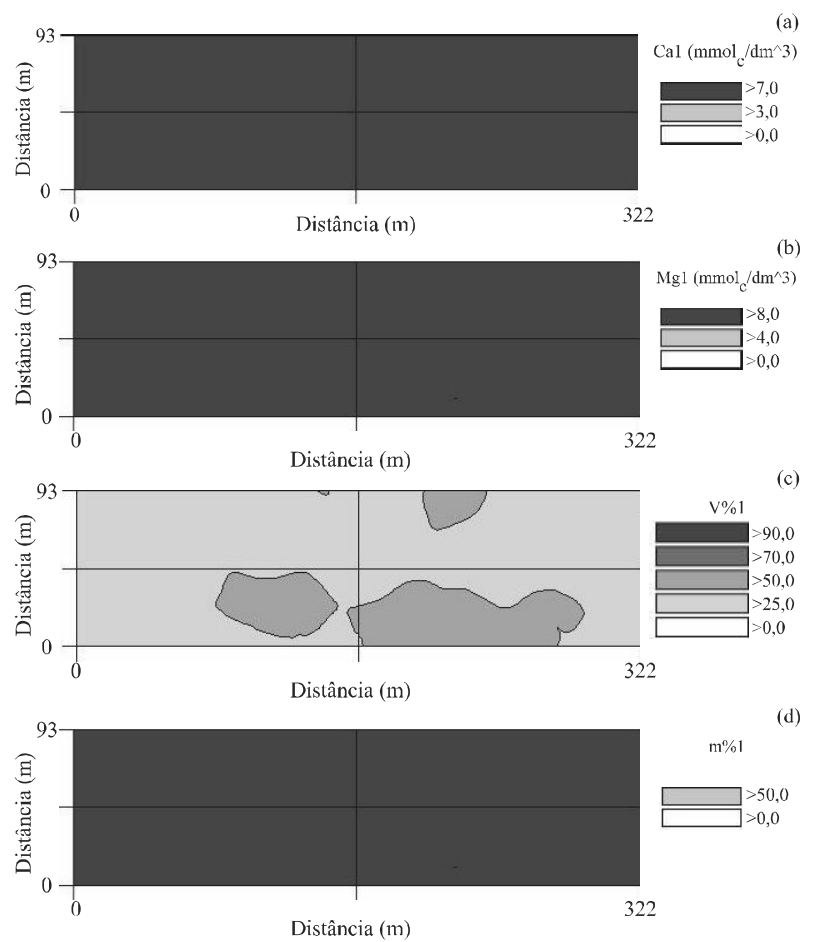

Figura 4 - Mapas de krigagem dos atributos químicos $(\mathrm{Ca}, \mathrm{Mg}$, V\% e m\%) de um Latossolo Vermelho Distroférrico sob sistema plantio direto na profundidade de 0,10 a $0,20 \mathrm{~m}$
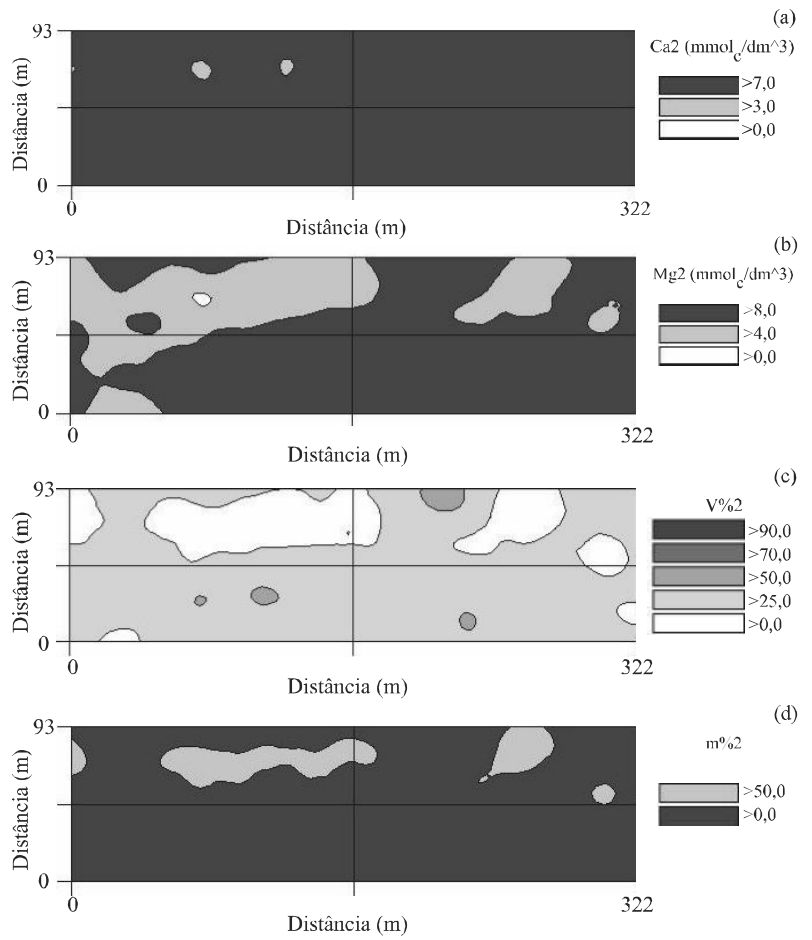
(Figura 2 e 4), com teor alto $\left(>7,0 \mathrm{mmol} \mathrm{dm}^{-3}\right)$. O mesmo não ocorreu com o $\mathrm{Mg}$, que apresentou homogeneidade horizontal somente na profundidade de 0 a $0,10 \mathrm{~m}$ (Figura $2)$, com teor alto $\left(>8,0 \mathrm{mmol}_{\mathrm{c}} \mathrm{dm}^{-3}\right)$. Contudo, na Figura 4 foi possível verificar que o teor alto deste nutriente foi mapeado numa área compreendendo $70 \%$ de toda a malha experimental. Em contrapartida, para o restante da área, o teor observado foi médio $\left(5,0-8,0 \mathrm{mmol}_{\mathrm{c}} \mathrm{dm}^{-3}\right)$. Os teores altos de $\mathrm{Ca}$ e $\mathrm{Mg}$ residuais ocorreram pelo fornecimento de quantidades consideráveis dessas bases trocáveis por ocasião da calagem.

A V\% apresentou-se com teores diferenciados entre as profundidades consideradas. Na Figura 2, seus índices aparecem como baixo (26,0-50,0\%), em maior proporção na área, e médio (51,0-70,0\%), ao passo que na Figura 4, foi possível verificar, além das classes citadas, a presença da classe muito baixa (0-25,0\%), representando expressiva área na malha experimental. Estes dados assemelham-se àqueles encontrados por Campos et al. (2007).

Em relação ao índice $\mathrm{m} \%$, na Figura 2 foi constatado que o solo é homogeneamente distrófico (m\% < 50,0\%). Por outro lado, verifica-se pela Figura 4 , na metade superior do mapa, que a $\mathrm{m} \%$ apresentou manchas contínuas de ambientes álicos, cuja $\mathrm{m} \%$ foi alta ( $\mathrm{m} \%>50,0 \%$ ), evidenciando regiões em que o efeito complexante do alumínio trocável foi menos intenso.

Particularmente para os atributos V\% e m\% (Figura 2 e 4), foi notada alta semelhança inversa. Assim, para aquelas regiões onde a V\% esteve compreendida entre $0-25,0 \%$, foram justamente as mesmas regiões onde a $\mathrm{m} \%$ foi superior a $50,0 \%$ (alta). Em contrapartida, nas demais regiões, a V\% foi superior a $25,0 \%$, enquanto que a $\mathrm{m} \%$ foi inferior a $50,0 \%$ (baixa).

De uma maneira geral, os resultados indicaram variabilidade espacial dos atributos químicos do solo, com teores variando desde a classe baixa até a classe alta. Por outro lado, os altos teores de cálcio e magnésio, os quais são atributos da fertilidade do solo utilizados como critérios para definição da necessidade e da quantidade de corretivo para neutralizar a acidez do solo, estavam homogêneos em toda a malha experimental. No entanto, a elevada acidez $(4,4<\mathrm{pH}<5,0)$ e a baixa saturação por bases (V\% < 50,0\%), evidenciaram a necessidade de realização de calagem na área, objetivando a homogeneização da fertilidade do solo, de maneira que as culturas agrícolas possam responder satisfatoriamente em produtividade.

\section{CONCLUSÕES}

1. As maiores variabilidades dos atributos químicos analisadas pelo coeficiente de variação ocorreram na camada de 0,10-0,20 $\mathrm{m}$ de profundidade;
2. Todos os atributos químicos pesquisados apresentaram dependência espacial, sendo possível mapear a área em estudo;

3. Os valores dos alcances da dependência espacial a serem empregados deverão estar compreendidos entre 40,2 e 113,1 metros.

\section{AGRADECIMENTO}

Os autores agradecem a Coordenação de Aperfeiçoamento de Pessoal de Nível Superior (CAPES) pela concessão de bolsa de pós-graduação ao primeiro autor.

\section{REFERÊNCIAS}

ALVES, M. C. et al. Ambiente de produção para a cana-deaçúcar cultivada nas propriedades agrícolas da Usina Vale do Paraná S/A Álcool e Açúcar. In: ALVES, M. C. et al. Estudo Agrotécnico da Usina Vale do Paraná S/A Álcool e Açúcar - Suzanápolis (SP). v. III. Ilha Solteira, 2009, 107 p.

AMADO, T. J. C. et al. Atributos químicos e físicos de LATOSSOLOS e sua relação com os rendimentos de milho e feijão irrigados. Revista Brasileira de Ciência do Solo, v. 33, n. 4, p. 831-843, 2009

CAMPOS, M. C. C. et al. Dependência espacial de atributos químicos em área cultivada com cana-de-açúcar em Pereira Barreto, SP. Revista Ciência Agronômica, v. 38, n. 4, p. 350-359, 2007.

CARVALHO, M. P.; TAKEDA, E. Y.; FREDDI, O. S. Variabilidade espacial de atributos de um solo sob videira em Vitória Brasil (SP). Revista Brasileira de Ciência do Solo, v. 27, n. 4, p. 695-703, 2003.

CHAVES, L. H. G.; FARIAS, C. H. A. Variabilidade espacial de cobre e manganês em Argissolo sob cultivo de cana-de-açúcar. Revista Ciência Agronômica, v. 40, n. 2, p. 211-218, 2009.

CORÁ, J. E. et al. Variabilidade espacial de atributos do solo para adoção do sistema de agricultura de precisão na cultura de cana-de-açúcar. Revista Brasileira de Ciência do Solo, v. 28, n. 6, p. 1013-1021, 2004.

COSTA, M. J. et al. Atributos químicos e físicos de um latossolo sendo influenciados pelo manejo do solo e efeito da gessagem. Acta Scientiarum: Agronomy, v. 29, p. 701-708, 2007. Suplemento.

DALCHIAVON, F. C. Aspectos da produtividade do arroz de terras altas irrigado com atributos químicos do solo sob plantio direto. 2010. 113 f. Dissertação (Mestrado em Agronomia) Universidade Estadual Paulista, Ilha Solteira, 2010.

DALCHIAVON, F. C. et al. Produtividade da soja e resistência mecânica à penetração do solo sob sistema plantio direto no 
cerrado brasileiro. Pesquisa Agropecuária Tropical, v. 41, n. 1 , p. 8-19, 2011.

DAVIS, J. C. Statistics and analysis in geology. 2. ed. New York: John Wiley, 1986. 646 p.

EMPRESA BRASILEIRA DE PESQUISA AGROPECUÁRIA. Sistema brasileiro de classificação de solos. 2. ed. Rio de Janeiro: Embrapa, 2006. 306 p.

FONTES, L. E. F.; FONTES, M. P. F. Glossário de ciência do solo. Viçosa: Departamento de Solos/UFV, 1992. 142 p.

Gamma Design Software. GS ${ }^{+}$: Geostatistics for environmental sciences. 7. ed. Michigan, Plainwell: Gamma Desing Software, 2004. 159 p.

LEMOS FILHO, L. C. A. et al. Variação espacial da densidade do solo e matéria orgânica em área cultivada com cana-de-açúcar (Saccharum officinarum L.). Revista Ciência Agronômica, v. 39, n. 2, p. 193-202, 2008.

MENDES, A. M. S.; FONTES, R. L. F.; OLIVEIRA, M. Variabilidade espacial da textura de dois solos do Deserto Salino, no Estado do Rio Grande do Norte. Revista Ciência Agronômica, v. 39, n. 1, p. 19-27, 2008.

RAIJ, B. V. et al. Análise química para avaliação da fertilidade de solos tropicais. Campinas: Instituto Agronômico, 2001. 285 p.

RAIJ, B. V. et al. Recomendação de adubação e calagem para o Estado de São Paulo. 2. ed. Campinas: Instituto Agronômico \& Fundação IAC, 1996. 285 p.
SCHLOTZHAVER, S. D.; LITTELL, R. C. SAS System for elementary statistical analysis. 2. ed. Cary, NC: SAS Institute Inc., 1999. $456 \mathrm{p}$.

SHAPIRO, S. S.; WILK, M. B. An analyze of variance test for normality: complete samples. Biometrika, v. 52, n. 3/4, p. 591-611, 1965.

SILVA, S. A. et al. Variabilidade espacial do fósforo e das frações granulométricas de um Latossolo Vermelho Amarelo. Revista Ciência Agronômica, v. 41, n. 1, p. 1-8, 2010.

SILVA, V. R. et al. Variabilidade espacial das características químicas do solo e produtividade de milho em um argissolo vermelho-amarelo Distrófico arênico. Revista Brasileira de Ciência do Solo, v. 27, n. 6, p. 1013-1020, 2003.

WERNER, V. et al. Aplicação de fertilizantes a taxa variável em agricultura de precisão variando a velocidade de deslocamento. Revista Brasileira de Engenharia Agrícola e Ambiental, v. 11, n. 6, p. 658-663, 2007.

ZANÃO JÚNIOR, L. A. et al. Variabilidade espacial de atributos químicos em diferentes profundidades em um latossolo em sistema de plantio direto. Revista Ceres, v. 57, n. 3, p. 429-438, 2010.

ZANÃO JÚNIOR, L. A.; LANA, R. M. Q.; GUIMARÃES, E. C. Variabilidade espacial do $\mathrm{pH}$, teores de matéria orgânica e micronutrientes em profundidades de amostragem num latossolo vermelho sob semeadura direta. Ciência Rural, v. 37, n. 4, p. 1000-1007, 2007. 